\title{
A EMANCIPAÇÃO RACIONAL DA MULHER: O PERIÓDICO O SEXO FEMININO E A LUTA FE- MININA POR DIREITOS SOCIAIS ÀS VÉSPERAS DA REPÚBLICA
}

\section{EMANCIPACIÓN RACIONAL DE LA MUJER: LA RE- VISTA $O$ SEXO FEMININO Y LA LUCHA FEMENINA POR LOS DEREHOS SOCIALES EM LA VÍSPERA DE LA REPÚBLICA}

Soraia Gatti ${ }^{l}$

Resumo: O presente trabalho tem por objetivo analisar os principais argumentos, pautas e questionamentos femininos presentes no periódico brasileiro $O$ Sexo Feminino, por meio de uma análise dos textos publicados em duas colunas do jornal, "A emancipação racional feminina" e "O casamento". A tônica emancipacionista e de enfrentamento à sociedade patriarcal brasileira são características que identificam o jornal e que conversam com os ideários do movimento feminista oitocentista europeu e norte americano. A emancipação da mulher pela educação e pela profissionalização era a pauta central do periódico. O periódico representa um profundo processo de redefinição da mulher na modernidade. Num momento em que se encontravam alijadas da participação política e em grande medida excluídas da vida pública, as mulheres encontraram na palavra escrita (e na publicação de suas ideias) uma estratégia de resistência e de luta política.

Palavras-chave: Emancipação feminina; Educação; Profissionalização; Feminismo; Escrita; Resistência.

Resumen: Este artículo tiene como objetivo examinar los principales argumentos, las directrices y las preguntas femeninas presentes en la

\footnotetext{
${ }^{1}$ Possui Ensino Médio Técnico em Eletrônica pela Universidade Tecnológica Federal do Paraná (UTFPR). Atualmente cursa graduação em História (Bacharelado e Licenciatura) pela Universidade Federal do Paraná (UFPR). Tem experiência na área de História, com ênfase em História Latino-Americana e História das Relações de Gênero.
} 
revista $O$ Sexo Feminino, a través de un análisis de los textos publicados en dos columnas del periódico, "La emancipación racional femenina" y "El matrimonio". El tónico emancipancionista y la frente a la sociedad patriarcal brasileña son características que identifican la revista y hablan con los ideales del movimiento feminista europeo y norteamericano del siglo XIX. La emancipación de la mujer mediante la educación y profesionalización fue la idea central del periódico. La revista muestra un profundo proceso de redefinición de las mujeres en la modernidad. En un momento en que fueron excluidas de la participación política y en gran medida excluidas de la vida pública, las mujeres encontraron en la palabra escrita (y en la publicación de sus ideas) una estrategia de resistencia y de lucha política.

Palabras-clave: Emancipación de la mujer; Educación; Profesionalización; Feminismo; Escrita; Resistencia.

\section{Introdução}

O presente trabalho tem por objetivo analisar os principais argumentos, teses, ideias, reivindicações e questionamentos femininos presentes no periódico $O$ Sexo Feminino, por meio de uma análise dos textos/artigos publicados em duas colunas do jornal, "A emancipação racional feminina" e "O casamento". O período analisado corresponde ao segundo semestre do ano de 1889, mais especificamente o mês de junho. Foram utilizadas para análise as duas primeiras edições do ano de 1889 (Ano III do periódico), disponíveis para consulta na hemeroteca digital da Biblioteca Nacional. A primeira edição (número 01) data de 02 de junho de 1889; e a segunda (número 02) de 09 de junho de 1889, período que é, portanto, imediatamente anterior à proclamação da República, em 15 de novembro de 1889. Após a mudança para a forma republicana de governo o periódico passou a se autodenominar simbolicamente de $O$ Quinze de Novembro do Sexo Feminino. 
Selecionamos o periódico O Sexo Feminino para discutir a problemática da emancipação da mulher às vésperas da República no Brasil pois sua linha editorial se voltava exclusivamente para as problemáticas sociais, políticas e culturais relacionadas às mulheres. A tônica emancipacionista dada pelo enfrentamento à sociedade patriarcal brasileira fazse presente e conversa com os ideários do feminismo oitocentista divulgado nos dois lados do Atlântico. Ao propor uma investigação acerca da representação, vinculada por este periódico específico, da figura psicológica, emocional, social, política e cultural da mulher, bem como ao perscrutar as formas de expressão femininas publicadas pelo jornal, este trabalho se insere em um terreno analítico que percebe as mulheres enquanto agentes, dialogando com as abordagens analíticas de gênero.

Outra questão (e também preocupação) que está implícita na elaboração deste artigo é o momento histórico-político-social no qual estes escritos foram produzidos: o ano da proclamação da República. Procurase investigar, neste sentido, se as teses e reflexões que ocupam as páginas do Sexo Feminino, revelam algum tipo de alinhamento político com a causa republicana.

Para começo de discussão, é importante refletir acerca do posicionamento e engajamento feminista do periódico. Neste sentido, torna-se importante historicisar a organização de mulheres e a reivindicação por direitos e autonomia, a fim de localizar e contextualizar a inserção e atuação do Sexo Feminino em uma luta social que tinha e tem, invariavelmente, caráter universal. 
O feminismo, enquanto movimento social e político, reúne pessoas que compartilham experiências, interesses e demandas comuns em torno da problematização dos direitos e da igualdade e teve suas primeiras expressões ainda na Europa setecentista, particularmente na França e Inglaterra, em meio às múltiplas transformações culturais, sociais, políticas e econômicas provocadas pelo avanço do capitalismo. (SANDENBERG \& COSTA, 1994). No Brasil, o pensamento feminista emerge de forma efetiva somente em meados do século XIX, com obras de autoras como Nísia Floresta Brasileira Augusta e a publicação da tradução parcial para o português da obra pioneira do movimento feminista A Vindication of the Rights of Woman ${ }^{2}$, de Mary Wollstonecraft, em 1832.

Desde então, o feminismo no Brasil, assim como em diversos lugares no mundo ocidental, vem assumindo diversas e diferentes formas, faces e bandeiras: sufragista, anarquista, socialista, comunista, burguesa, reformista. O Sexo Feminino se apresenta como porta voz do feminismo no Brasil reivindicando o direito à educação e à profissionalização feminina e, após a proclamação da República, passou a defender o sufrágio feminino. Essas demandas e reivindicações, como a ampliação da educação e profissionalização da mulher, são encontradas repetidamente nas matérias publicadas no jornal e constituem o material analisados neste artigo (presentes nas duas primeiras edições de 1889, o Ano III do periódico).

\footnotetext{
${ }^{2}$ Publicação original em 1792, Inglaterra.
} 
É importante enfatizar que as lutas feministas no Brasil não constituem um lugar à parte na história social e cultural. O movimento feminista, ao qual o periódico $O$ Sexo Feminino incontestavelmente se alinha, é reconhecido pela história das mulheres como engajado e incorporado à dinâmica da sociedade brasileira. Prova disto é o fato já exposto de que, com a República, o periódico aqui estudado passa a se nomear $O$ Quinze de Novembro do Sexo Feminino. Ato simbólico, mas também expressivo e insinuante, que possui claramente uma postura política e demonstra como há um diálogo entre o projeto feminista defendido pelo jornal e as mudanças estruturais pelos quais o Brasil estava passando.

Com a proclamação da República e a extensão do direito ao voto para todos os homens alfabetizados, abria-se a promessa e a possiblidade de uma estrutura política mais igualitária. É neste contexto que começa a luta pelos direitos políticos das mulheres, a começar pelo direito ao voto extensivo às mulheres. Com o advento do período republicano, o Quinze de Novembro do Sexo Feminino, passou a assumir um caráter profundamente sufragista (NASCIMENTO \& OLIVEIRA, 2007).

\section{O Sexo Feminino: origens e ideário}

O Sexo Feminino foi um periódico criado na cidade de Campanha da Princesa (MG) em 1873, pela educadora Francisca Senhorinha da Motta Diniz, mineira de São João d'El Rei, proprietária, redatora e editora oficial do jornal. Com a mudança de Francisca Diniz para a Corte do Império Brasileiro, o jornal passou a ter sua sede no Rio de Janeiro. As publicações aqui circularam, portanto, naquela cidade. 
Ao contrário de um livro, que geralmente possui apenas um autor, os jornais são formados por um grupo de autores que escrevem a partir de uma linha de pensamento comum. No caso do Sexo Feminino, as escritoras e jornalistas eram mulheres, muitas intelectuais, que ao se engajarem e se reunirem em torno do projeto da emancipação feminina construíram redes de sociabilidades e contribuições mútuas a fim de delinear uma identificação e postura sólida para o jornal (TEIXEIRA, 2011).

As principais colaboradoras do periódico, segundo Teixeira, eram as três filhas de Francisca Diniz: Amélia, Albertina e Elisa Diniz; além de diversas outras mulheres que eventualmente publicavam, como a jornalista Violante Ataliba Ximenes de Bivar e a poeta Narcisa Amália. Nas duas edições analisadas, O Sexo Feminino apresentou-se enquanto um "semanário literário, recreativo e noticioso", "especialmente dedicado aos interesses da mulher". As colaboradoras eram, de fato, segundo apresentação do periódico ao início de cada edição, "suas filhas e diversas senhoras".

Tais declarações inferem o caráter coletivo do jornal: escrever principalmente para mulheres e com a colaboração de diferentes mulheres, que defendiam os interesses e as demandas sociais femininas. Trata-se, portanto, de uma rede de sociabilidade entre mulheres tecida em torno do periódico.

Todos os textos analisados presentes nas duas primeiras edições do ano de 1889, não foram assinados. Pode-se inferir deste fato uma possível intenção e esforço contínuo do periódico em enfatizar o caráter 
coletivo do projeto editorial. Os artigos presentes nas colunas analisadas foram, inclusive, escritos em primeira pessoa do plural.

A maioria das escritoras do Sexo Feminino era composta por mulheres urbanas, letradas e intelectuais, especialmente ligadas ao magistério primário, com opções e opiniões religiosas diferenciadas, que migraram do interior do Brasil para a Corte. Elas enfrentaram muitas dificuldades para publicar suas ideias, em razão da falta de dinheiro ou mesmo do preconceito social que partia, inclusive, também de outras mulheres de seu tempo. Algumas trabalharam arduamente pela causa abolicionista, embora esta participação feminina seja pouco conhecida e estudada pela historiografia (TEIXEIRA, 2011, p. 05).

A trajetória da fundadora e proprietária do Sexo Feminino, Francisca Diniz, é elucidativa para a compreensão das linhas políticas e culturais do jornal, bem como o lugar que ele ocupava no meio cultural da época. Diniz atuou no magistério primário do Rio de Janeiro e de São Paulo, escreveu um romance sobre costumes (A Judia Rachel), dirigiu colégios e foi editora e colaboradora de outros periódicos, tais como $A$ Voz da Verdade e A Primavera. Tendo dedicado boa parte de sua vida ao ensino, nada mais natural que o seu periódico hasteasse a bandeira da educação e profissionalização feminina. O grande inimigo das mulheres, segundo Diniz, era a ignorância, o desconhecimento e a falta de reivindicação dos seus direitos, o que as tornaria escravas e não companheiras em pé de igualdade com os homens. Defendia a tese de que a solução para a subordinação estaria numa efetiva participação da mulher na sociedade (TEIXEIRA, 2011, p. 06). A análise feita neste trabalho 
das colunas "A emancipação racional da mulher" e "O Casamento", presentes nas duas edições selecionadas demonstrou, de fato, que a essência do jornal, sua bandeira principal, era a defesa da independência e emancipação social da mulher pela educação racional.

As duas colunas analisadas figuravam entre a primeira e a segunda página do periódico, que geralmente possuía quatro páginas. O Sexo Feminino também publicava poesias, receitas, dicas de moda e beleza, trechos de pensamentos filosóficos e literários diversos referentes à figura feminina. Estes temas, entretanto, eram secundários; a ênfase estava no engajamento social e político em prol da defesa dos direitos das mulheres.

\section{"A Racional Emancipação Feminina" e "O Casamento"}

A emancipação racional feminina, conforme enunciada na primeira edição, seria orientada pelos princípios da igualdade, da fraternidade e da liberdade (aqui, temos uma clara referência ao ideário revolucionário, o que demonstra como as ideias geradas na Europa tinham profunda influência e encontravam ressonância na sociedade brasileira de então). Tais princípios se distanciam e até mesmo se opõem profundamente à instituição da escravidão, um grilhão ao verdadeiro aperfeiçoamento moral e intelectual de uma sociedade, segundo o Jornal. O abolicionismo está presente no discurso do jornal como causa de liberdade, à qual as mulheres também deveriam aderir.

O conceito de "civilização da humanidade" é evocado pelo periódico no contexto do século XIX, tido como o século das luzes e da "ba- 
talha pela civilização". Tal momento histórico não podia deixar de conter também a batalha pela racional emancipação da mulher. Esta questão é considerada pelo periódico como o problema mais sério e de maior importância a ser resolvido para que a civilização triunfasse com plenitude.

A independência feminina é vista, portanto, como um problema de difícil dinâmica, mas que precisava ser enfrentado e superado. Sua resolução, invariavelmente, seria de alcance, e diria respeito, a ambos os sexos. A emancipação seria assim transcendente ao universo feminino, tendo ampla abrangência social. Seria também "um passo fundamental a favor do progresso da humanidade".

Destes princípios pode-se concluir que o periódico é enfático ao afirmar que enquanto as mulheres não fossem efetivamente livres e autônomas a civilização e o progresso não triunfariam. A evocação de conceitos como "civilização", "progresso da humanidade" e "século das luzes" demonstra a profunda influência do pensamento liberal e reformista na visão e percepção que essas mulheres redatoras do Sexo Feminino tinham acerca da História, da civilização e da sociedade.

A união feminina, o caráter coletivo, o sepultamento dos preconceitos e, inclusive, a paciência e a perseverança, são elementos que aparecem nos textos como necessários ao enfrentamento das opressões e injustiças sociais. O jornal se apresenta, neste sentido, como o porta-voz da mulher e da defesa de seus direitos, direitos esses "até hoje pouco prezados ou com revoltante injustiça postergados" (pág. 01; edição núm.01). 
Em uma época em que a ciência havia estabelecido a igualdade de inteligência entre homens e mulheres, segundo o discurso do periódico, a sociedade moderna deveria educar a mulher não exclusivamente para "a glória ou o ornamento de salões", mas para também serem úteis à humanidade.

Uma questão interessante, encontrada nos textos analisados, diz respeito à percepção e compreensão da complexidade das "dimensões da vida" pelo jornal. A vida teria dimensão íntima e pessoal, social e pública. As mulheres não poderiam ficar restritas ao âmbito doméstico e privado, elas tinham direito a mais, a provarem a diversidade de experiências que a "ciência da vida" proporciona aos indivíduos: "A vida não é uma cousa simples; há a vida física, a moral e a intelectual, e também a vida da família, do indivíduo e da sociedade. O aperfeiçoamento [...] da mulher não é uma utopia: é ideia realizada" (pág.01-02; edição núm. 01). O periódico defende, portanto, que o aperfeiçoamento da mulher é algo concreto, realizável e que, por isso, precisaria ser perseguido e alcançado. Cabe ressaltar que o jornal defendia, portanto, a ampliação das esferas de atuação das mulheres, uma postura política ousada para a época.

A "regeneração da humanidade" é outro conceito que aparece como dependente da atuação social da mulher e, principalmente, da sua ação na família, vista como a sociedade em miniatura, um microcosmo ou um núcleo fundamental da comunidade civil. Neste sentido, O Sexo Feminino assume um discurso reformador. Tal regeneração ou "reforma" da sociedade dependia da educação dos jovens, a qual o jornal de- 
fende que devia ser realizada exclusivamente por mulheres e mães, já que "nem é mais permitido negar-se a sua superioridade [da mulher] na instrução e educação da mocidade” (pág. 02, edição núm. 01).

Percebe-se a defesa de uma superioridade feminina em relação ao homem: "Neste século [XIX] a mulher acompanharia passo a passo o progresso intelectual do homem, tendo mesmo provado superioridade no mundo moral e sensível. Para provar o que acabamos de avançar, temos inúmeros fatos tanto na história antiga, como na média e contemporânea. " (Pág. 02, edição núm. 01). Para provar tal argumento, a Lei do Ventre Livre de 1871 e a Lei Áurea de 1888, ambas assinadas pela princesa Isabel, representada como uma heroína pelo jornal, são citadas como exemplos da energia, capacidade e iniciativa da mulher.

A princesa Isabel é vista e representada, neste sentido, como a verdadeira responsável pela abolição da escravatura no Brasil e a grande redentora dos escravos: "Sem a Princesa Imperial D. Isabel, o que seria da mísera raça, que há tanto tempo era oprimida pela escravidão? " (Pg. 02, edição núm. 01). Neste ponto, é necessário reconhecer que tal visão apresentada pelo periódico a respeito dessas leis abolicionistas é idealista e ignora os conflitos e debates em torno destas questões políticas e econômicas, criando uma representação idealizada e sem ancoragem histórica da Princesa Isabel. No entanto, interpretamos que se tratava de uma estratégia discursiva do jornal, com o intuito de distinguir a ação moral benfazeja das mulheres. Outros elementos historicamente associados à imagem feminina que são contestados nos textos analisados dizem às ideias de fraqueza e tutela. A mulher, pelo contrário, seria 
capaz de superar dificuldades muitas vezes irresolutas para os homens: "Sem Cornellia, o que fariam os Grachos? Quem libertaria do poder do feroz Holofernes o seu povo oprimido senão a meiga Judith? ” (Pág. 02, edição núm. 01). Tais referências, a Cornellia e os Grachos ${ }^{3}$ e a Holofernes e Judith ${ }^{4}$ ilustram o caráter culto, intelectual e literário do periódico, que reunia contribuições de escritoras letradas.

A emancipação pela educação aparece repetidamente, como na passagem: "Vejamos, pois, boas mães, o terreno é nosso, não o deixemos sem cultura [...]; a principal ideia é de abrir todas as carreiras ao nosso deprimido sexo por meio da instrução ministrada pela mãe de família” (pág. 02, edição núm. 01). Observa-se a defesa de que as mães deveriam ser as mais atuantes educadoras de seus próprios filhos e filhas, uma vez que a influência feminina na educação seria fundamental para a formação de uma nova geração de mulheres emancipadas.

As referências bíblicas, à Providência e à figura divina, bem como à instituição da família, são recorrentes no jornal, o que demonstra uma grande influência da religião, especialmente do Cristianismo, sobre o pensamento das redatoras do Sexo Feminino.

O patriarcado aparece como o tema central do espaço "A emancipação racional da mulher" na segunda edição analisada, de 09 de junho de 1889. A coluna nesta edição tem como subtítulo "A mulher perante a História". A crítica direciona-se especialmente ao patriarcado quando o

\footnotetext{
${ }^{3}$ Evocação à obra "Triunfos de Francisco Petrarca" de Luiz de Camões.

${ }^{4}$ História bíblica que se refere ao povo assírio; há uma famosa pintura, do pintor italiano Michelangelo Merisi de Caravaggio, em que Judith decapita Holofernes, um cruel general assírio que atuava a mando de Nabucodonosor.
} 
mesmo se manifesta e se relaciona com a instituição do casamento e das relações amorosas: "Que triste a condição da mulher nas eras que chamamos patriarcais! Não era o seu olhar amante que buscava na turba de homens o esposo escolhido de sua alma. $O$ direito de escolha pertencia ao pai ou aos irmãos mais velhos. O seu dever era seguir o esposo designado, embora desconhecido. Simples eram as cerimônias nupciais: a entrega do dote e as dadivas dos parentes constituíam a base do casamento" (p. 01; edição núm. 02). Tais reflexões demonstram a melancolia com a qual $O$ Sexo Feminino percebia a subordinação da vontade da mulher à autoridade masculina nos assuntos afetivos.

A estrutura patriarcal da sociedade e a subordinação da mulher são vistas inclusive como um sintoma de atraso e barbárie: "A condição social da mulher marca exatamente o grau de civilização de um povo" (p. 01; edição núm. 02). Notemos a profundidade de tal declaração e posicionamento. A situação da mulher é o ponto de inflexão por meio da qual pode-se avaliar a elevação social e moral de uma sociedade: “[...] onde a mulher é rainha, a sociedade é culta, onde a mulher é escrava, é bárbara a sociedade” (p. 01; edição núm. 02). Tal noção é expressada pelo jornal como uma "verdade", uma "lei histórica", observada entre os primitivos aryas (grupo étnico indo-europeu) e na sociedade védica indiana, por exemplo.

Tal discurso apresenta, portanto, elementos de justificação/comprovação que se baseiam em leituras feitas acerca de fatos históricos e de diferentes sociedades; demonstra também o convicto posicionamento de Francisca Diniz e suas colaboradoras da profunda impor- 
tância que a emancipação da mulher assume dentro do conceito de "civilidade" e "progresso" da sociedade. A emancipação feminina pela educação é a grande causa e bandeira do periódico e não estava alheio às dinâmicas políticas, sociais e econômicas, muito pelo contrário, é uma pauta fundamental, pois uma sociedade na qual a condição da mulher é ignorada e que as mulheres não lutam por seus direitos, só podia ser uma sociedade bárbara, atrasada, na qual não havia liberdade, igualdade nem fraternidade.

Os argumentos presentes na coluna "O Casamento" retomam uma série de teses. Os dois espaços analisados, em verdade, se complementam, se confundem: a causa é comum. Também aqui, num espaço do periódico destinado a discutir a condição da mulher dentro do matrimônio, a emancipação da mulher e a igualdade de direitos apresentam-se como as bases fundamentais de legitimidade e justiça desta instituição social.

O casamento, tal como apresentado no Sexo Feminino na primeira edição analisada, uniria dois indivíduos, em caráter permanente/eterno, com o fim do aperfeiçoamento mútuo dos indivíduos e da constituição da família (vista como molécula fundamental da sociedade). O matrimônio teria também base religiosa; a religião seria uma "autoridade superior" que guiaria os "movimentos diversos" dos dois cônjuges.

O regimento, ou o ordenamento e dinâmica de uma família (cuja constituição é o objetivo principal do casamento) não pode ser absoluto ou despótico, mas deve ser ilustrado, racional, prudente e moderado. Neste sentido, o texto defende que não deve haver desigualdade de di- 
reitos entre o marido e sua esposa: há uma severa crítica ao "império da proeminência marital" e à superioridade concedida pelas leis do código civil brasileiro da época aos maridos. Tal disposição de coisas atentaria contra a dignidade moral da mulher e a impediria de exercer, por exemplo, atividades profissionais como a de escritora ou preceptora sem a prévia autorização do marido. O periódico, com este discurso, mais uma vez enfatiza a importância da educação e profissionalização da mulher como vias racionais para a emancipação feminina, dentro e também fora do casamento.

Na segunda edição analisada, a coluna "O casamento" apresenta essencialmente os argumentos anteriores, que se repetem e ganham reforço. A tutela marital é criticada e considerada sintoma de injustiça. A emancipação é novamente enfatizada: ela não é uma ilusão utópica, é uma necessidade ajustada à realidade. Para sua realização seria necessária uma convicta repressão a todos os obstáculos diretos e indiretos, por meio de uma prudente e reflexiva revisão do código civil, a fim de garantir a igualdade de direitos entre os sexos. A educação, enfim, aparece reiteradamente como o substrato fundamental: "A razão esclarecida dicta a lei suprema” (p.01, edição núm. 02). Somente por meio da instrução a mulher poderia se emancipar, conquistar direitos e aperfeiçoar suas capacidades: “É preciso que as mulheres se vão habilitando a tornarem-se cidadãs úteis, porque são verdadeiros membros do corpo político e interessam diretamente com a ordem social e com o bom regimento dos negócios públicos” (p. 02, edição núm. 02). 
O teor discursivo do periódico mostrou-se combativo e confiante; fazia uma convocatória às mulheres para que reivindicassem seus direitos por meio da via segura da educação, da profissionalização e da razão: "Ousamos reclamar para o nosso sexo a emancipação. Os tradicionais podem rir a vontade de nossa audácia [...] Isso não nos deterá no caminho que traçamos” (p. 01, edição núm. 02). “Avante, pois, amáveis conterrâneas” (p. 02, edição núm. 01).

Por meio da leitura do periódico e da análise realizada é importante refletir a respeito de uma última pergunta: para quais mulheres, afinal, o jornal se dirigia? A princípio, O Sexo Feminino pode ser compreendido como um periódico criado, administrado e escrito por uma elite letrada de mulheres; os textos publicados por elas faziam referências literárias cultas, de difícil acesso para a maioria das mulheres brasileiras de então. Além disso, o discurso dirigia-se, sobretudo, às ditas "mães de família", haja vista as inúmeras passagens nas quais a instituição familiar é exaltada, ressaltada e vista a partir de uma perspectiva moral cristã.

Contudo, a causa defendida pelo jornal era universal, dizia respeito a uma concepção universal de mulher, o que pretensamente incluía mulheres ricas e pobres, brancas ou negras, religiosas ou não. A emancipação da mulher, por meio da razão e educação, é uma questão que atinge e diz respeito à universalidade do gênero feminino, era o que defendiam suas colaboradoras. Por isso, mesmo que a totalidade do discurso e do pensamento reproduzidos pelo jornal não fosse compreensível ou acessível em termos intelectuais e culturais à totalidade das 
mulheres, defendemos que o ímpeto emancipacionista de sua mensagem era universal e se dirigia a todas as mulheres.

\section{Considerações finais}

As análises e reflexões realizadas acerca do discurso feminista presente no periódico $O$ Sexo Feminino nos levam a concluir que a emancipação da mulher pela educação e pela profissionalização era a pauta central do periódico, e do movimento feminista de modo geral, naquele momento. A religião e atuação da mulher dentro da família, entendida como sociedade em miniatura e a principal instituição de reforma social, aparecem como elementos complementares no interior da causa central de emancipação racional feminina. A mulher adquire nas páginas do periódico um status de agente civilizatório de fundamental importância, o ponto de inflexão por meio do qual se "mede" o grau de "civilização" de uma sociedade.

Em período impulsionado pelos ideais de progresso, civilização e modernização, as estruturas sociais e políticas do país modificavam-se. O período imediatamente anterior e posterior à proclamação da República, e o ano de 1889 especificamente, exigiu todo um processamento de reengenharias sociais e políticas no Brasil. Tal reestruturação se estendia também à condição social das mulheres. Neste sentido, o periódico $O$ Sexo Feminino reflete e representa um profundo processo de redefinição da mulher na modernidade. Num momento em que se encontravam alijadas da participação política e em grande medida excluídas da vida pública, as mulheres encontraram na palavra escrita (e na publi- 
cação de suas ideias) uma estratégia de resistência, de entrada na esfera pública e de defesa do protagonismo público e social das mulheres.

\section{Fonte Primária}

O Sexo Feminino. Ano III. Núm. 01 e 02. Rio de Janeiro, 1889. In: Hemeroteca Digital da Biblioteca Nacional. Disponíveis em:

$<$ http://memoria.bn.br/DocReader/DocReader.aspx?bib=706868\&PagFi s=0\&Pesq> Acesso em: 08/10/2016.

\section{Bibliografia}

COSTA, Ana Alice A.; SANDENBERG, Cecília M. B. Feminismos, feministas e movimentos sociais. In: Mulher e relações de gênero. BRANDÃO, Margarida Luiza Ribeiro; BINGEMER, Maria Clara L. (Orgs.). São Paulo: Edições Loyola, 1994. Pp. 81-112.

NASCIMENTO, Cecília Vieira do; OLIVEIRA, Bernardo J (coautor). O Sexo Feminino em campanha pela emancipação da mulher. In: $\mathrm{Ca}$ dernos Pagu. Julho-dezembro de 2007. pp. 429-457.

TEIXEIRA, Roberta Guimarães. Os lugares e os meios de sociabilidade intelectual do jornal O Sexo Feminino (1873-1889): algumas considerações. In: VI Congresso Brasileiro de História e Educação, 2011, Vitória - ES. Invenção, tradição e escrita da História da Educação no Brasil. UFES, 2011. 